\title{
AL-A'RAF
}

Jurnal Pemikiran Islam dan Filsafat

SURAKARTA

http://ejournal.iainsurakarta.ac.id/index.php/al-araf

ISSN: 1693-9867 (p); 2527-5119 (e)

DOI: $10.22515 /$ ajpif.v14i2.910

\section{DULKADIRAN, MEDIA MASYARAKAT SAMPURNAN UNTUK MEMPEROLEH KESELAMATAN, PAHALA, SYAFAAT, DAN SURGA}

\author{
Nilna Fadlillah \\ UIN Sunan Kalijaga, Yogyakarta
}

\begin{tabular}{l}
\hline \\
\hline Keywords: \\
Dulkadiran, \\
Living Qur'an, \\
Interpretation of \\
cultures \\
\hline
\end{tabular}

\begin{abstract}
Abstrak
Tulisan ini mencoba menggambarkan praktik pembacaan Alqur'an dalam tradisi Dulkadiran yang dilakukan oleh masyarakat Sampurnan secara etnografis, guna mengetahui makna yang terkandung di dalamnya. Melalui teori interpretasi budaya ditemukan bahwa masyarakat Sampurnan mengenal konsep-konsep yang didasarkan pada landasan agama yang mempunyai ultimate meaning sebagai cara untuk mendapatkan keselamatan, pahala, dan surga. Konsepkonsep itu kemudian dipercaya sebagai konsep yang benar dan nyata, yang selanjutnya dirumuskan dalam bentuk simbol-simbol yang terdapat dalam tradisi Dulkadiran. Simbol-simbol tersebut memiliki makna yang kembali kepada konsep-konsep tersebut dan menyarankan suatu gaya hidup atau tindakan, yang disampaikan oleh para Kyai secara persuasif. Melalui konsep-konsep itulah kemudian masyarakat termotivasi untuk melaksanakan tradisi Dulkadiran. Pelaksanaan tradisi ini memunculkan perasaan dalam diri seseorang yang kemudian direfleksikan dalam kehidupan sehari-hari, seolah-olah membenarkan konsep yang ada, sehingga perasaan tersebut secara unik terlihat realistis.
\end{abstract}

\section{Abstract}

This paper tries to describe the practice of reading Qur'an in the Dulkadiran tradition practiced by Sampurnan society ethnographically, in order to find its meaning. Based on the interpretation of cultures theory found out that the Sampurnan society recognizes the concepts that are based on the religious basis, which has ultimate meaning as a way to get the salvation, reward, and paradise. These concepts were then believed as the true and real, which then formulated into various symbols in the Dulkadiran tradition. These symbols have meaning that refers to those concepts and suggested certain lifestyle or action, which 
is delivered persuasively by Kiyai. Through those concepts, people were then motivated to perform Dulkadiran tradition. The practice of this tradition was able to create moods of a person, which then reflected into the daily life, and felt as if to justify the existing concepts, so the motivations and moods seem uniquely realistic.

\section{Pendahuluan}

Alqur'an memiliki peran yang sangat penting bagi umat Islam. Selain sebagai sumber ajaran, Alqur'an juga diyakini sebagai mukjizat. Bagi yang membacanya akan mendapat pahala dan keistimewaan-keistimewaan lainnya. Oleh sebab itu tidak heran bila setiap hari, di berbagai tempat dan situasi, umat Islam senantiasa membaca Alqur'an. Berbagai model pembacaan, mulai dari sekedar membaca sebagai ibadah ritual, membaca untuk memahami maknanya, hingga model pembacaan untuk berbagai kepentingan tertentu, seperti mendatangkan kekuatan magis, pengobatan, dan tujuan lainnya. ${ }^{1}$ Model pembacaan yang terakhir ini, oleh Van Voorst dikategorikan sebagai penggunaan kitab suci dari segi performative. Dalam hal ini, Alqur'an sebagai kitab suci dialami dan memiliki kekuatan untuk mempengaruhi dan merubah kehidupan masyarakatnya. ${ }^{2}$ Alqur'an difungsikan sebagai alat untuk memberkahi, mengobati, dilombakan, dan sebagainya.

Fenomena semacam ini, dalam kajian Islamic studies masuk dalam kajian living qur'an atau resepsi Alqur'an. Yakni, suatu kajian atau uraian bagaimana seseorang menerima dan bereaksi terhadap Alqur'an dengan cara menerima, merespon, memanfaatkan atau menggunakannya, baik sebagai teks yang memuat susunan sintaksis, atau sebagai mushaf yang memiliki maknanya sendiri. ${ }^{3}$ Salah satu contoh fenomena living qur'an

\footnotetext{
2014), 104.

Abdul Mustaqim, Metode Penelitian Alqur'an dan Tafsir (Yogyakarta: Idea Press,

2 Van Voorst, "Kajian Naskah dan Kajian Living Qur'an dan Living Hadith," Journal of Qur'an and Hadith Studies 4, no. 2 (2015): 151.

3 Ahmad Rafiq, "Sejarah Alqur'an: dari Pewahyuan ke Resepsi (Sebuah Pencarian
} 
ditemukan dalam tradisi Dulkadiran yang praktekkan oleh masyarakat Sampurnan, dusun Nongkokerep, kecamatan Bungah, kabupaten Gresik, Jawa Timur. Dulkadiran merupakan kegiatan yang bertujuan untuk memohon sesuatu kepada Allah dengan melakukan wasilah kepada Syekh Abdul Qadir Aljilani. Tradisi ini dilakukan dengan membaca suratsurat tertentu di dalam Alqur'an. Biasanya, Dulkadiran dilakukan ketika seseorang memiliki hajat tertentu. ${ }^{4}$

Berdasarkan fenomena di atas, tulisan ini berusaha mengulas praktik pembacaan Alqur'an dalam tradisi Dulkadiran yang dilakukan oleh masyarakat Sampurnan dan makna yang terkandung di dalam praktik tersebut, dengan menggunakan teori interpretasi budaya, dengan pendekatan etnografis. ${ }^{5}$

\section{Tradisi Dulkadiran di Sampurnan ${ }^{6}$}

Istilah Dulkadiran diambil dari susunan kata Abdul Qadir yang dinisbatkan kepada Syekh Abdul Qadir Aljilani. Tradisi ini bertujuan memohon sesuatu kepada Allah melalui wasilah kepada Syekh Abdul Awal Metodologis)," in Islam, Tradisi, dan Peradaban, ed. Sahiron Syamsuddin (Yogyakarta: Suka Press, 2012), 73.

4 Wawancara dengan KH. Ahmad Bukhari Hadi, pemimpin Dulkadiran, di Sampurnan, pada tanggal 27 April 2015.

5 Etnografi adalah suatu kegiatan yang tujuannya untuk memahami suatu pandangan hidup dari sudut pandang penduduk asli.

6 Sampurnan terletak di desa Bungah, kecamatan Bungah, kabupaten Gresik, provinsi Jawa Timur. Keberadaan Sampurnan sangat berkaitan erat dengan sejarah pendirian pondok pesantren Qomaruddin yang terdapat di wilayah ini. Pada tahun 1775 $\mathrm{M}$, terdapat seorang ulama yang berasal dari Bonang, Lasem, Jawa Tengah bernama K.H. Qomaruddin datang dari Lamongan. Kedatangan beliau ke Gresik untuk mencari tempat yang cocok untuk didirikan pesantren. Setelah melakukan pengembaraan, beliau sampai di suatu tempat yang terletak antara Masjid Kyai Gede Bungah dan Kantor Distrik Bungah. Di sinilah, pada tahun $1775 \mathrm{M}$, beliau mulai mendirikan pondok pesantren. Lalu Kanjeng Tumenggung Tirtorejo, Tumenggung Gresik pada saat itu yang pernah menjadi santri asuh KH. Qomaruddin memberi nama pesantren tersebut dengan nama pondok pesantren Sampurnan. Nama Sampurnan merupakan akronim dari kata sampurno temenan (benar-benar sempurna). Lihat Abdul Rauf Djabir, Dinamika Pondok Pesantren Qomaruddin (Gresik: YPP Qomaruddin, 2014), 15-16. 
Qadir Aljilani, seorang wali yang dikenal memiliki karamab ${ }^{7}$ luar biasa. ${ }^{8}$ Tradisi Dulkadiran di dusun Kauman, Comal, Pemalang ${ }^{9}$ dan dusun Palang Kab. Tuban, ${ }^{10}$ dilaksanakan dengan membaca Manaqib Syekh Abdul Qadir Aljilani.

Adapun Dulkadiran yang berlangsung di Sampurnan ini dilaksanakan dengan membaca surat Alfatihah, surat Yasin, surat Alwaqiah, surat Alsyam, surat $A l d u b a$, surat Alinsyirah, surat Alqadr, surat Alikblas, surat Alfalaq, dan surat $A$ lnas. Setelah itu dilanjutkan dengan membaca sebagian dari Alasma' Albusna (Ya Hadi, Ya 'Alim, Ya Khabir, Ya Mubin) sebanyak 100 kali. ${ }^{11}$ Di samping itu, dalam kegiatan Dulkadiran ini terdapat hidangan khas, yaitu nasi uduk dan ayam jago. Hidangan ini merupakan hidangan yang selalu diberikan oleh penyelenggara kepada para tamu undangan yang mengikuti kegiatan. Konon, nasi uduk dan ayam jago merupakan makanan favorit Syekh Abdul Qadir Aljailani. ${ }^{12}$

Menurut Kyai Bukhari, tradisi Dulkadiran dapat dilakukan kapan saja, sesuai dengan kehendak orang yang mempunyai hajat. Akan tetapi saat ini, Dulkadiran yang sering dilakukan oleh masyarakat Sampurnan adalah ketika seseorang mempunyai hajat mendoakan kerabat yang akan, atau sedang pergi jauh. Seperti haji, pernikahan, dan haul masyayikh.

7 Tanda karamah yang dimiliki oleh Syekh Abdul Qadir Aljilani sudah dirasakan oleh ibunya sejak kecil. Beliau tidak mau menyusu di siang hari pada akhir bulan Sya’ban dan selama bulan Ramadhan, sehingga hal itu menjadi tanda datangnya bulan puasa tiap-tiap bulan. Lihat A. Aziz Masyhuri, Ensiklopedi 22 Aliran Tarekat (Surabaya: Imtiyaz, 2014), 211.

8 Diolah dari hasil wawancara dengan K.H. Ishaq Abdurrahman, tokoh masyarakat dan ulama' masyarakat Sampurnan, di Sampurnan, pada tanggal 26 April 2015

9 Ahmad Ta'rifin, “Tafsir Budaya atas Tradisi Barzanji dan Manakib,” Penelitian 7, no. 2 (2010).

${ }^{10}$ Nur Syam, Islam Pesisir (Yogyakarta: LkiS, 2005). 2015.

11 Diolah dari hasil wawancara dengan K.H. Ahmad Bukhari Hadi, pada 27 April

12 Diolah dari hasil wawancara dengan K.H. Ahmad Bukhari Hadi, pada 27 April 2015.

AL-A'RAF - Vol. XIV, No. 2, Juli - Desember 2017 
Di Sampurnan, tradisi ini pertama kali dibawa oleh KH. Musthofa, menantu KH. Moh. Sholih Tsani. ${ }^{13}$ Berdasarkan ijazah ${ }^{14}$ yang diterima oleh Kyai Bukhari, Kyai Musthofa mendapatkan ijazah tradisi ini dari gurunya, Kyai Cholil Bangkalan. ${ }^{15}$ Selanjutnya, ketika Kyai Musthofa pindah ke Kranji, Lamongan untuk mendirikan pesantren sendiri di sana, tradisi ini dilanjutkan oleh para pengasuh pesantren selanjutnya, di antaranya K.H. Ismail ${ }^{16}$ dan K.H. Sholih Musthofa. ${ }^{17}$ Kemudian, secara terus-menerus tradisi ini ditransmisikan kepada para Kyai periode selanjutnya dan tetap dilestarikan hingga saat ini.

\section{Praktik Pembacaan Alqur'an dalam Tradisi Dulkadiran ${ }^{18}$}

Pada musim haji tahun 2015, Ibu Khoiriyah, warga dusun Sampurnan, mengadakan acara Dulkadiran yang ketiga kalinya untuk mendoakan anak dan menantunya yang sedang melaksanakan ibadah haji. Sebagaimana biasanya, acara dilaksanakan selepas shalat Isya', sekitar pukul 19.00 WIB. Acara dimulai sesaat setelah Kyai Bukhari, Kyai sekaligus tokoh di dusun ini, hadir. Kyai Bukhari duduk di dekat pintu, menghadap ke arah kiblat, lalu menyiapkan bacaan-bacaan Dulkadiran.

${ }^{13}$ KH. Moh. Sholih Tsani adalah pemangku PP Qomaruddin yang ke 5.

${ }^{14}$ Izin yang diberikan oleh guru kepad muridnya untuk mengajarkan ilmu yang diperoleh murid dari gurunya. Lihat KBBI Offline Vers. 1.5.

15 Diolah dari hasil wawancara dengan K.H. Ahmad Bukhari Hadi, pada 27 April 2015.

16 K.H. Ismail adalah kakak ipar sekaligus adik ipar Kyai Musthofa. Adik Kyai Ismail yang bernama Nyai Aminah menikah dengan Kyai Musthofa. Sedangkan Kyai Ismail menikah dengan Nyai Zainab, adik dari Kyai Mushtofa. Setelah Kyai Musthofa pindah ke Lamongan dan mendirikan PP Tarbiyatut Thalabah, Kyai Ismail yang sebelumnya tinggal di rumah mertua, diminta pulang ke Sampurnan untuk menjadi pemangku PP Qomaruddin ke 6 melanjutkan kepemimpinan ayahnya yaitu KH. Moh. Sholih Tsani. Diolah dari hasil wawancara dengan KH. Ahmad Bukhari Hadi, pemimpin Dulkadiran, di Sampurnan, pada 27 April 2015.

17 K.H. Sholih Musthofa adalah putra dari K.H. Musthofa yang kemudian menjadi pemangku PP Qomaruddin ke 7.

${ }_{18}$ Hasil observasi terhadap pelaksanaan Dulkadiran di rumah Ibu Muslichah pada tanggal 28 September 2015. 
Setelah dibuka dengan bacaan Surat Alfatihah, acara dilanjutkan dengan Dulkadiran yang dipimpin oleh Kyai Bukhari. Sebelum memulai, beliau mengucapkan salam lalu menyampaikan kepada para undangan bahwa maksud dari Dulkadiran ini adalah untuk berdoa bersama-sama, agar anak dari Kyai Muslih yang sedang melaksanakan ibadah haji selalu berada dalam lindungan Allah dan menjadi haji yang mabrur:

"Kados adatipun, acara Dulkadiran inggib niku berdoa bersama, ngalap barokah saking panjenenganipun Syekh Abdul Qadir Aljilani, mugimugi putranipun Bapak. Kyai Muslih ingkang kesah dateng Makkah Almukarramah mugi-mugi senantiasa dalem lindunganipun Allah, sehingga estu-estu saget memperoleh haijan mabruran wa sa'yan masykuran wa dzanban maghfuran." 19

Acara Dulkadiran pun diawali oleh Kyai Bukhari dengan bacaan surat Alfatihah yang ditujukan kepada beberapa pihak. ${ }^{20}$ Kemudian dilanjutkan dengan membaca surat-surat Alqur'an secara tadwir. ${ }^{21}$ Bacaan beliau ini diikuti oleh para peserta dengan serentak dan khidmat. Pada pelaksanaan Dulkadiran kali ini, surat-surat Alqur'an yang dibaca adalah surat Yasin, Alwaqiah, Alsyams, Alduha, Alinsyirah, Alqadr, Altakasur, Alfil, Alquraisy, Alnasr, dan surat yang dibaca masing-masing tiga kali, yaitu Alikblas Alfalaq, dan Alnas. ${ }^{22}$

19 Perkataan K.H. Ahmad Bukhari Hadi yang disampaikan sebelum memulai acara Dulkadiran di rumah Ibu Muslichah pada tanggal 28 September 2015.

${ }^{20}$ Pertama, Nabi Muhammad, keluarga, dan para sahabat. Kedua, kepada para nabi, malaikat, orang-orang yang syahid, orang-orang shalih, Nabi Adam dan Hawwa'. Ketiga, kepada Khulafa' Alrasyidin, sahabat, tabi’in, tabi' Altabi’in. Keempat, kepada empat imam madzhab, para ulama', para qurra', imam hadith, mufassir, sufi, wali, dan orang-orang muslim. Kelima, kepada para Syekh Qadiriyah dan Naqsabandiyah terkhusus kepada Syekh Abdul Qadir Aljilani, dst. Keenam, kepada orang tua, guru, orang-orang yang berbuat baik dan buruk, dst. Ketujuh, kepada seluruh orang islam baik yang masih hidup ataupun yang sudah meninggal. Kedelapan, kepada Syekh Abdul Qadir Aljilani. Secara bersamasama, Surat Alfatibah ini dibaca satu persatu sebanyak delapan kali sesuai dengan jumlah kelompok di atas.

21 Membaca Alqur'an secara tadwir yaitu membaca Alqur'an dengan kecepatan sedang (antara pelan dan cepat) disertai dengan memperhatikan hukum-hukumnya. Lihat Abd Al-Qayyum, Safahat fi 'Ulum Alqira'ah (Makkah: Almaktabah Alimdadiyyah, 2001).

22 Menurut penjelasan Kyai Bukhari, biasanya surat-surat yang dibaca pada 
Usai membaca surat-surat Alqur'an beliau melanjutkan dengan mengucapkan zikir Ya Hadi, Ya Alim, Ya Khabir, Ya Mubin. Dengan menggunakan tasbihnya dan sedikit menggerakkan badannya, dengan khusyu' membaca zikir tersebut sebanyak 100 kali. Para undangan juga tetap pada posisinya mengikuti bacaan zikir Kyai Bukhari. Setelah hitungan ke 100, beliau membaca zikir tersebut sekali lagi dengan tempo melambat, untuk mengganjilkan hitungan sekaligus sebagai tanda bahwa bacaan zikir telah selesai. Acara kemudian diakhiri dengan bacaan doa.

Ketika doa dibacakan oleh Kyai Bukhari, seluruh undangan menunduk dengan mengangkat kedua tangannya. Sementara para peserta mengamini doa tersebut dengan suara lirih. Sekitar delapan menit kemudian, beliau menutup doa Dulkadiran dengan bacaan surat Alfatibah. Setelah itu, beliau membaca sya'ir pujian kepada para auliya', ulama' dan anbiya'.

Setelah pembacaan doa, Kyai Bukhari pun menutup rangkaian acara Dulkadiran dengan membaca doa kafarat almajlis sebanyak tiga kali, dilanjutkan dengan bacaan tasbih dan tahmid. Setelah itu, hidangan nasi uduk dan kari ayam yang telah disiapkan di piring-piring dikeluarkan oleh para ibu dari dapur. Sebagaimana biasa dilakukan di Sampurnan, hidangan

saat Dulkadiran adalah Surat Yasin, Surat Alwaqi'ah, Surat Alsyams, Surat Alduha, Surat Alinsyirah, Surat Alqadr, Surat Alikhlas, Surat Alfalaq, dan Surat Alnas. Akan tetapi, dari beberapa pelaksanaan Dulkadiran yang dipimpin oleh beliau sendiri, surat-surat pendek yang dibaca berbeda-beda. Ada yang sesuai dengan keterangan beliau, ada yang ditambah dengan Surat Alfil dan Alnasr, ada juga yang ditambah dengan Surat Altakasur, Surat Alfil, Surat Alquraisy, dan Surat Alnasr. Ketika hal ini dikonfirmasi, beliau menjelaskan bahwa sebenarnya, bacaan yang diijazahkan dari Kyai Cholil adalah Surat Alkahfi, Surat Alsajdah, Surat Yasin, Surat Alwaqi'ah, Alsyams, kemudian membaca Surat Alduha sampai Alnas. Bacaan inilah yang dulu digunakan oleh para Kyai. Kemudian, pada masa Kyai Murtadlo, Kyai Abdul Karim, dan Kyai Abdul Hadi, surat-surat tersebut tidak dibaca seluruhnya, tetapi dibaca beberapa saja karena mempertimbangkan situasi masyarakat. Kemudian, pada masa Kyai Thohir Adlan, surat panjang yang dibaca ketika Dulkadiran di Sampurnan hanya Surat Yasin dan Alwaqiah. Akhirnya, ketika diminta memimpin Dulkadiran di Sampurnan, Kyai Bukhari mengikuti kebiasaan yang sudah berjalan. Untuk surat-surat pendek, beliau mengikuti tata cara para Kyai sebelumnya, yaitu membaca surat-surat yang sudah biasa dibaca dan mudah dihafal masyarakat. 
terlebih dahulu diberikan kepada Kyai Bukhari untuk memuliakannya. Baru setelah itu, hidangan dibagikan kepada para undangan.

Sekitar pukul 20.30 WIB setelah semua yang hadir menikmati hidangan yang telah disajikan, berkat yang telah disiapkan sejak maghrib pun satu per satu dibagikan kepada para undangan. Beberapa tetangga yang berhalangan hadir juga diberi, dititipkan kepada undangan yang rumahnya berdekatan. Setelah semua mendapat berkat, Kyai Bukhari pun memberikan komando untuk berdiri dengan mengucapkan shalawat. Para undangan pun serentak menjawab shalawat sambil berdiri. Satu per satu undangan mendekat kepada Kyai Bukhari dan Kyai Mushlih. Secara bergantian mereka bersalaman dan meminta undur diri.

\section{Memaknai Tradisi Dulkadiran}

Bagi Clifford Geertz, selain menggambarkan fenomena budaya suatu masyarakat, tugas utama antropolog adalah menemukan makna yang ada di balik fenomena tersebut, berdasarkan apa yang diketahui, dirasakan, dan dialami oleh pelaku budaya. Inilah yang disebut Geertz sebagai from the native point's of view, yang merupakan hakikat dari pemahaman antropologis. ${ }^{23}$ Proses menemukan makna dan nilai yang ada di balik simbol-simbol kehidupan, yang diekspresikan oleh suatu masyarakat dan memahaminya dari sudut pandang mereka merupakan konsep dari antropologi interpretatif.

Melalui simbol, ide, dan adat-istiadat, Geertz menemukan pengaruh agama berada di setiap sudut kehidupan masyarakat. ${ }^{24}$ Berdasarkan hal inilah, ia menyimpulkan agama sebagai suatu sistem kebudayaan:

"A religion is (1) a system of symbols which acts to (2) establish powerful, pervasive, and long lasting moods and motivations in men by (3) formulating conceptions of a general order of existence and (4) clothing these conceptions with such an aura of factuality that (5) the moods and motivations seem uniquely realistic." 25

23 Nur Syam, Madzhab-Madz̧ab Antropologi (Yogyakarta: LKiS, 2011), 93.

${ }^{24}$ Daniel L. Pals, Seven Theories of Religion, n.d, 341.

25 Clifford Geertz, The Interpretation of Cultures (USA: Basic Books, 1973), 90. 
Bagi Geertz, agama merupakan (1) satu sistem simbol yang bertujuan untuk (2) menciptakan perasaan dan motivasi yang kuat, mudah menyebar, dan tidak mudah hilang dalam diri seseorang (3) dengan cara membentuk konsepsi tentang sebuah tatanan umum eksistensi dan (4) membungkus konsepsi-konsepsi ini dengan aura faktualitas (5) sehingga perasaan dan motivasi ini secara unik akan terlihat realistis. Dengan elemen teori ini, tradisi pembacaan surat-surat Alqur'an dalam tradisi Dulkadiran di dusun Sampurnan dapat dilihat sebagai sistem simbol. Di dalam Dulkadiran terdapat simbol-simbol yang mampu menciptakan perasaan dan motivasi yang unik dalam diri seseorang.

\section{Memuliakan Ulama'}

Hampir semua tradisi yang dilakukan oleh masyarakat Sampurnan adalah tradisi yang dibawa atau diajarkan oleh para Kyai. Dari generasi ke generasi, para Kyai mengajarkan, menganjurkan, dan mengajak masyarakat untuk melakukan berbagai tradisi, termasuk Dulkadiran. Dengan peran Kyai tersebut, masyarakat Sampurnan selalu berusaha untuk melestarikan tradisi yang telah diajarkan oleh para Kyai sebelumnya. Terkait dengan hal ini, Kyai Ishaq mengatakan bahwa ajaran yang dibawa oleh para Kyai adalah salah satu petunjuk bagi santrinya, sehingga perlu diamalkan. ${ }^{26}$

Bagi masyarakat Sampurnan, Kyai memiliki otoritas tinggi dalam hal agama. Karena otoritas itulah, masyarakat merasa perlu memuliakan para Kyai dengan mengamalkan tradisi yang telah diajarkan, dan meminta doa atau ngalap berkah kepada para Kyai. Sebagaimana disampaikan oleh Ibu Lucha, bahwa dengan memuliakan ulama, orang akan mendapatkan keselamatan dunia-akhirat dan mendapatkan kebaikan atau keberkahan. ${ }^{27}$ Di sinilah terlihat bagaimana peran sentral seorang Kyai dalam tatanan kehidupan sosial masyarakat secara umum, tida tidak hanya sebatas dalam

${ }^{26}$ Diolah dari hasil wawancara dengan K.H. Ishaq Abdurrahman, pada 26 April 2015.

27 Wawancara dengan Ibu Masluchah, pada tanggal 25 Desember 2015 
lingkungan pesantren. Bahkan peran tersebut tidak hanya menyangkut urusan keagamaan, tetapi juga dalam hal sosial, ekonomi, budaya, maupun politik. Peran sentral inilah yang oleh Geertz kemudian memberikan istilah Kyai sebagai "Cultural Broker" bagi masyarakat di Indonesia. ${ }^{28}$ Selain itu, pandangan ini secara substansi, juga dipengaruhi oleh konsep agama tentang keutamaan memuliakan ulama. Salah satu konsep tersebut terdapat di dalam hadith yang diriwayatkan oleh Alkhatib Albaghdadi dari Jabir r.a.:

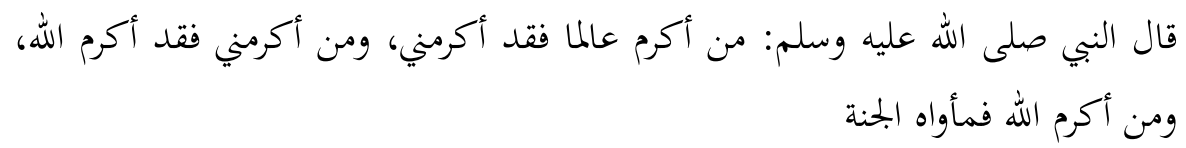

"Nabi SAW bersabda: "Barangsiapa memuliakan orang 'alim, berarti ia telah memuliakan aku. Barangsiapa memuliakan aku, berarti memuliakan Allah. Barang siapa memuliakan Allah, maka tempat kembalinya adalah surga." 29

Hadith di atas menjelaskan bahwa orang yang memuliakan ulama akan mendapatkan surga, sebagai tempat kembali. Sementara masyarakat Sampurnan memahaminya sebagai cara untuk mendapatkan keselamatan, kebaikan, dan keberkahan. Di sini terlihat suatu ultimate meaning, yaitu memperoleh keselamatan, kebaikan, dan keberkahan.

\section{Birru Alwalidain}

Selain memuliakan para Kyai, masyarakat Sampurnan juga berusaha untuk berbuat baik kepada para orang tuanya. Salah satu caranya, dengan menjaga dan melestarikan tradisi yang telah dilakukan oleh para orang tua pendahulu mereka. Terkait dengan hal ini, Pak Isa pernah menyampaikan perkataan Kyai Ahmad Maimun Adnan: ${ }^{30}$

28 Nur Kafid, "From Personal to Social Transformation: A Phenomenological Study on the Life of 'Kyai Kampung," JURNAL KOMUNITAS: Research \& Learning in Sociology and Anthropology 6, no. 2 (2014): 336-344.

${ }_{29}$ Alsuyuti, Lubab Alhadith (Surabaya: Nur Alhuda, n.d.), 8.

30 K.H. Ahmad Maimun Adnan adalah pengasuh Pondok Pesantren Al-Islah yang terletak di dekat Sampurnan. Beliau juga merupakan salah satu keturunan K.H. 
"Wes ditinggali ngunu kok kari nerusno wae kok ga gelem. Ninggali Sunnah gak iso, kok ngelakuni Sunnah sing wis ditinggali wong tuo wae kok gak gelem, "Birru aba akum tabirrukum abnaukum”. Bagusono wong tuwomu, nek. kepengen dibagusi anak-anakmu. Nah salah sijine coro mbagusi wong tuo iku yo nerusno sunnabe wong tuo.' ${ }^{\prime 31}$

Menurut Isa, dengan berbuat baik kepada orang tua, masyarakat meyakini bahwa nanti anak-anak mereka juga akan berbuat baik kepada mereka. Dalam hal ini meneruskan tradisi yang ada, diyakini sebagai bagian dari patuh dan taat keapada orang tua. Melalui tradisi Dulkadiran ini mayarakat meyakini, bahwa selain mendapatkan untuk diri sendiri, pahala yang diperoleh juga akan mengalir kepada orang tua mereka. Dengan demikian, terdapat suatu ultimate meaning dari konsep tentang birru alwalidain, yaitu mendapatkan kebaikan dan pahala.

\section{Keistimewaan Alqur'an}

Masyarakat Sampurnan meyakini bahwa bacaan-bacaan di dalam tradisi Dulkadiran adalah bacaan yang baik. Terlebih, bacaan intinya adalah surat-surat Alqur'an. Masyarakat Sampurnan meyakini Alqur'an sebagai pedoman yang penuh keutamaan. Di antaranya adalah mendatangkan pahala bagi para pembacanya. Sebagaimana yang diungkapkan dalam riwayat hadith dari Abdullah bin Mas’ud.

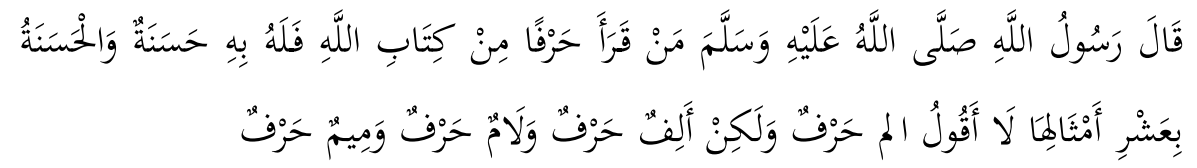

"Rasulullah shallallahu 'alaibi wasallam bersabda: "Barangsiapa membaca satu huruf dari Kitabullah (Alqur'an), maka baginya satu pahala kebaikan dan satu pahala kebaikan akan dilipat gandakan menjadi sepuluh kali, aku tidak mengatakan Alif Lam Mim itu satu huruf, akan tetapi Alif satu huruf, Lam satu huruf dan Mim satu huruf." 32

Qomaruddin dan menjadi salah satu panutan masyarakat Sampurnan selama masa hidupnya.

31 Wawancara dengan Bapak Ahmad Isa, pemimpin Dulkadiran, di Sampurnan, pada tanggal 5 Maret 2016.

32 Sunan Altirmizi, “Kitab Fadail Alqur’an ‘an Rasulillah No. 2835,” n.d. 
Selain itu, Alqur'an juga memberikan keuntungan bagi pembacanya saat di akhirat nanti. Dalam riwayat hadith lain, Nabi pernah memerintahkan para sahabat untuk membaca Alqur'an, karena di hari kiamat nanti ia akan menjadi syafaat bagi pembacanya. ${ }^{33}$ Bahkan Alqur'an juga memiliki keutamaan lain, berupa keuntungan duniawi. Misalnya, dalam beberapa riwayat hadith disebutkan bahwa membaca Surat Albaqarah dapat melindungi pembacanya dari kekuatan sihir. Ada juga riwayat hadith yang menyebutkan bahwa membaca surat Alwaqi'ah dapat menjauhkan pembacanya dari kefakiran. ${ }^{34}$ Akan tetapi di balik keuntungan duniawi ini, konsep tentang keistimewaan Alqur'an memiliki suatu tujuan pasti, yaitu kebaikan ketika di akhirat, karena pembacanya akan mendapatkan pahala dan syafaat Alqur'an.

\section{Aura Faktualitas}

Geertz mengatakan bahwa agama, atau perspektif relijius memperdalam pemusatan perhatiannya kepada fakta dan berusaha menciptakan aura faktualitas (mengandung kenyataan atau kebenaran). Pengertian tentang sesuatu yang "sungguh nyata" ini adalah pusat dari kegiatan-kegiatan yang disimbolkan oleh agama. ${ }^{35}$

Konsep agama tentang memuliakan ulama yang ada di masyarakat Sampurnan memunculkan aura faktualitas, sehingga akan tampak sebagai konsep yang dipercaya mengandung kebenaran. Konsep tentang otoritas atau kemuliaan ulama, memiliki landasan dari hadith Nabi yang menyatakan bahwa orang yang memuliakan ulama akan mendapatkan surga sebagai tempat kembali. Landasan inilah yang membuat konsep tersebut memunculkan aura faktualitas, sehingga dipercaya sebagai konsep yang benar dan nyata.

33 Sahih Muslim, "Kitab Salatu Almusafirin No. 1337," n.d.

34 Alazkar Alnawawi, Tilawah Alqur'an No. 323 (Beirut: Dar Al-Fikr, 1994), 111.

35 Clifford Geertz, Kebudayaan dan Agama (Terj), ed. Francisco Budi Hardiman (Yogyakarta: Kanisius, 1992), 32. 
Begitu juga dengan konsep berbuat baik kepada orang tua, dan keistimewaan Alqur'an. Kedua konsep tersebut memiliki landasan hadith Nabi yang menyatakan bahwa dengan berbuat baik kepada orang tua, anak-anak mereka kelak juga akan berbuat baik kepada mereka. Dalam konteks ini, mereka juga memahami bahwa jika seorang anak melakukan Dulkadiran yang sebelumnya telah dilakukan oleh orang tuanya, maka ia telah berbuat baik dengan mengirimkan pahala kepada orang tuanya. Begitu juga dengan membaca Alqur'an, seseorang akan mendapatkan pahala dan syafaat ketika di hari akhir nanti. Semua konsep tersebut bersumber dari hadith yang kemudian memunculkan aura faktualitas. Dengan munculnya aura ini, konsep-konsep agama tersebut dipercaya oleh masyarakat sebagai sesuatu yang benar dan nyata.

\section{Sistem Simbol}

Suatu sistem simbol adalah segala sesuatu yang memberikan ideide kepada seseorang. ${ }^{36}$ Dalam konteks ini, ide-ide itu bersumber dari konsep-konsep agama. Konsep-konsep agama yang memiliki ultimate meaning, kemudian memunculkan aura faktualitas, pada tahap selanjutnya dirumuskan dalam bentuk simbol. Simbol ini kemudian disampaikan oleh otoritas dengan gaya persuasif, yang menyarankan suatu gaya hidup atau tindakan tertentu. Dalam konteks ini tindakan tersebut berupa pelaksanaan tradisi Dulkadiran. Adapun simbol-simbol yang terdapat di dalam Dulkadiran antara lain:

\section{Simbol 1: Surat-Surat Alqur'an}

Sebagaimana telah dijelaskan pada sub judul sebelumnya, bahwa masyarakat Sampurnan meyakini konsep tentang keistimewaan Alqur'an. Konsep tersebut kemudian dirumuskan dalam simbol pembacaan suratsurat Alqur'an. Praktik Dulkadiran di Sampurnan memang sedikit berbeda

\footnotetext{
36 Daniel L. Pals, Seven Theories of Religion, 343.
} 
dengan praktik pada umumnya yang menggunakan pembacaan manaqib di dalamnya. Dulkadiran di Sampurnan, dilaksanakan dengan membaca suratsurat dalam Alqur'an. Terkait dengan penggunaan Alqur'an dalam tradisi Dulkadiran, Kyai Bukhari menjelaskan.

"Coro Tawasshule niku maos qur'an. Nek penjelasane Yai Sholeb Musthofa, Jelase kirim nang Syekh Abdul Qadir Aljilani qur'an sak Khatame. Nek kaet alif lam mim yo kesuen, moco Aldhuba sampe Alnas yo khataman qur'an. Nek gak iso yo sak, gampange. Nek, aku yo tak, petel sak gampange wae. ${ }^{137}$

Adapun makna surat-surat yang dibaca ketika tradisi Dulkadiran dapat dilihat dari pandangan dua lapis masyarakat, yaitu menurut para tokoh dan menurut masyarakat umum:

1) Makna menurut para tokoh

Sebagai orang yang langsung mendapat ijazah Dulkadiran, Kyai Bukhari menjelaskan bahwa makna pembacaan surat-surat Alqur'an dalam tradisi Dulkadiran adalah ta'abbudan li amrillab—ibadah untuk melaksanakan perintah Allah. Pandangan ini dilatarbelakangi oleh pengalaman beliau dalam dunia tarekat. Sebagai pengikut tarekat Qadiriyah Naqsabandiyah, beliau memahami pembacaan Alqur'an semata-mata untuk beribadah kepada Allah. Menurut beliau, mencari makna atau maksud pembacaan Alqur'an tidak perlu dilakukan, meskipun ada pendapat yang mengatakan, misalnya membaca Surat Alwaqiah itu akan memperluas rizki atau memudahkan segala sesuatu. Bagi beliau, itu hanyalah hadiah, bukan tujuannya. Beliau menganalogikan hal ini dengan orang yang menyebrangi sungai, lalu mendapatkan kesegaran. Tujuannya adalah sampai ke sebrang, tetapi kemudian ia mendapatkan kesegaran sungai. Sama halnya dengan membaca Alqur'an dalam Dulkadiran, tujuan utamanya adalah melaksanakan perintah Allah. Jika kemudian seseorang mendapatkan keluasan rizki atau yang lainnya, maka itu adalah hadiah dari Allah. ${ }^{38}$

37 Wawancara dengan K.H. Ahmad Bukhari Hadi, pada tanggal 30 November 2015.

38 Wawancara dengan K.H Ahmad Bukhari Hadi, pada tanggal 27 April 2015. 
Sedikit berbeda dengan pendapat Kyai Bukhari, Kyai Ishaq menjelaskan bahwa surat-surat Alqur'an itu memiliki fadhilah tersendiri. ${ }^{39}$ Secara umum, Alqur'an dapat menjadi obat, rahmat, dan cahaya bagi pembacanya. Akan tetapi masing-masing bagiannya memiliki keistimewaan tersendiri. Kyai Ishaq memberikan penjelasan tentang keutamaan surat Yasin, Alwaqi'ah, dan Alikhlas. Di antara keutamaan surat Yasin itu dapat menyelamatkan seseorang dari musibah dunia-akbirat. Kyai Ishaq mengutip potongan hadith tentang keutamaan surat Yasin, Takabadu 'anbu balwa al-dunya wa al-akbirah, yang menurutnya, meski tidak secara langsung menyebutkan sumber badith tersebut, akan tetapi itu bisa dilacak dan ditemukan di dalam beberapa literatur, salah satunya di dalam Jami' Almasanid wa Almarasil karya Alsuyuti. ${ }^{40}$

Sedangkan untuk keutamaan surat Alwaqi'ah, Kyai Ishaq menjelaskan bahwa surat ini dapat menghindarkan manusia dari kemiskinan. Keterangan ini ditemukan di dalam beberapa kitab hadith, seperti halnya yang secara khusus keutamaan Alqur'an:

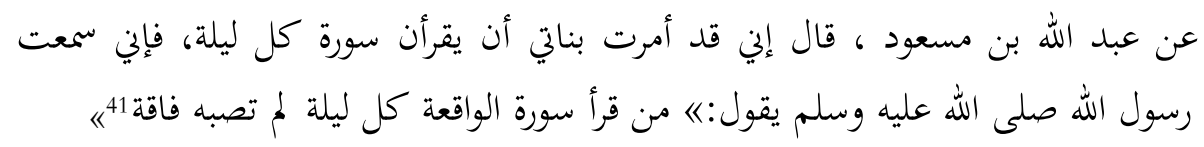

Dari Abdullah bin Mas'ud, ia berkata: Sungguh aku memerintahkan kepada anak-anak perempuanku untuk membaca Surat Alwaqi'ah setiap malam, karena sesungguhnya aku telah mendengar Rasulullah saw. bersabda: "Barangsiapa membaca Surat Alwaqi'ah setiap malam maka kefakiran tidak akan menimpanya."

39 Wawancara dengan K.H. Ishaq Abdurrahman, pada tanggal 26 April 2015.

40 Alsuyuti, Jami' Almasanid wa Almarasil, Jilid 5, 10. Riwayat ini juga ditemukan di dalam Alqurtubi, Altizkar fi Afdali Alazkar, 274 dan Aldurais, Fadail Alqur'an, 100. Di dalam keterangannya Alsuyuti menilai da'if riwayat yang disandarkan kepada Abu Bakar yang juga terdapat di dalam riwayat Aldurais.

${ }^{41}$ Alqasim bin Salam, "Fadail Alqur'an wa Ma'alimuhu Wa Adabuhu," n.d. Riwayat ini juga ditemukan di dalam Alazkar Alnawawi, Tilawah Alqur'an No. 323 (Beirut: Dar Alfikr, 1994), 111.; Ibnu Hajar Al'asqalani, Almatlab Al'aliyah, Jilid 7. (Beirut: Dar Alkutub Alilmiyyah, 2003), 286.; Albaihaqi, Syu'bu Aliman, Jilid 2. (Beirut: Dar Alkutub Alilmiyyah, 2000).; Aldurais, "Fadail Alqur'an," n.d, 103..; Alqurtubi, "Altizkar fi Afdali Alazkar," n.d, 287. 
2) Makna menurut masyarakat umum

Secara umum, masyarakat memaknai surat-surat yang dibaca dalam pelaksanaan tradisi Dulkadiran sebagai sarana berdoa. Mereka mengaitkannya dengan tujuan pelaksanaan Dulkadiran. Sebagaimana diungkapkan oleh $\mathrm{Bu}$ Kho, bahwa Dulkadiran adalah amrib keselametan. Menurutnya, Dulkadiran dilakukan untuk mendoakan kerabat yang sedang pergi haji agar diberi keselamatan dan menjadi haji yang mabrur. Pembacaan Alqur'an di dalamnya merupakan sarana untuk mencapai tujuan itu. ${ }^{42}$

Makna yang sama juga disampaikan oleh Bu Barrotut Taqiyah, bahwa semua yang dibaca dalam proses Dulkadiran itu adalah kalimat-kalimat yang baik. Melalui pembacaan itu, orang meminta pertolongan kepada Allah agar segala sesuatu yang diinginkan, atau yang akan dilakukan berjalan lancar dan dijaga keamanannya, sehingga memperoleh keselamatan. ${ }^{43}$

Disamping itu, masyarakat juga memaknai pembacaan Alqur'an sebagai sarana mendapatkan pahala dan keberkahan, sebagaimana yang disampaikan oleh Bapak Husnun:

"Membaca Alqur'an itu kan ibadah. Karena ibadah, jika dilakukan maka akan mendapat balasan pahala. Di mana saja, di rumah, di masjid, meskipun dibaca ketika Dulkadiran seperti ini, sama saja. Tapi ketika Dulkadiran seperti ini itu kan ada harapan tertentu, misalnya mendoakan orang yang haji. Nah itu, dengan membaca Alqur'an, semoga bisa memberkahi, ya memberkahi orang yang mendoakan, juga orang yang didoakan.” ${ }^{44}$

Pandangan lain disampaikan oleh Aswadi, dengan latar belakang keilmuan tafsir yang dimiliki, ia memaknai surat-surat tersebut dengan menggali ruh yang terkandung di dalam setiap surat. Baginya, pembacaan surat-surat Alqur'an tersebut adalah sarana untuk menguatkan keimanan kepada Allah. Ia menemukan makna itu lewat memahami rub yang terdapat di dalam setiap surat. Menurutnya, jike a sudah

42 Hasil wawancara dengan Ibu Khoiriyah, penyelenggara tradisi Dulkadiran, di Sampurnan, pada tanggal 1 Desember 2015.

43 Diolah dari hasil wawancara dengan Ibu Nyai Hj. Barrotut Taqiyyah, penyelenggara tradisi Dulkadiran, pada tanggal 26 April 2016.

44 Wawancara dengan Bapak Husnun Nashir, partisipan tradisi Dulkadiran, di Sampurnan, pada tanggal 5 Maret 2016. 
iman dan selalu mendekatkan diri kepada Allah, persoalan yang lain-lain menjadi mudah. Sebab iman itu ruh kehidupan, iman bahwa Allah itu bisa mengubah segala sesuatu yang tidak mungkin dilakukan secara rasional. ${ }^{45}$

\section{Simbol 2: Tawassul kepada Syekh Abdul Qadir Aljilani.}

Konsepsi tentang kemuliaan ulama dipercaya dapat mengantarkan masyarakat Sampurnan untuk mendapatkan keselamatan dan kebaikan. Cara yang dilakukan untuk memuliakan ulama dilakukan dengan patuh, mengikuti para Kyai dan ngalap berkah kepada mereka. Konsep ini dirumuskan dalam bentuk tawassul. ${ }^{46}$ Tawassul ini bentuknya bermacammacam, antara lain, ada yang dilakukan dengan melakukan amal-amal saleh, menyebut nama orang-orang yang dekat dengan Allah baik yang masih hidup maupun yang telah meninggal dunia. Tawassul dengan cara inilah yang dilakukan masyarakat Sampurnan dalam tradisi Dulkadiran. Mereka ber-tawassul kepada kepada Syekh Abdul Qadir Aljilani dengan cara membaca surat-surat Alqur'an.

Meskipun masyarakat Sampurnan tidak mengikuti tarekat Qadiriyah, di mana Syekh Abdul Qadir Aljilani sebagai pendirinya, akan tetapi mereka meyakini bahwa Syekh Abdul Qadir Aljilani adalah Sultan Alauliya'. Masyarakat menilai dan meyakininya sebagai orang yang dekat dengan Allah. Sebagaimana diungkapkan oleh Rofiqoh, bahwa Syekh Abdul Qadir Aljilani itu Wali Quthub, walinya para wali, yang kewaliannya sudah mu'tabarah. Sehingga namanya sering disebut setelah Nabi Muhammad ketika akan berdoa, dengan harapan agar melalui beliau, Allah akan mendengar dan mengabulkan doanya. ${ }^{47}$ Pendapat senada juga disampaikan

45 Wawancara dengan Bapak Aswadi, penyelenggara dan partisipan Dulkadiran, di Sampurnan, pada tanggal 25 Desember 2015.

46 Tawassul didefinisikan sebagai upaya mendekatkan diri kepada Allah dengan menggunakan wasilah. Wasilah merupakan sesuatu yang menyambung dan mendekatkan seseorang dengan Allah atas dasar keinginan yang kuat dari yang bersangkutan untuk mendekat kepada-Nya. Quraish Shihab, Wawasan Alqur'an tentang Drikir dan Doa (Jakarta: Lentera Hati, 2006).

${ }^{47}$ Diolah dari hasil wawancara dengan Ibu Rofiqoh, partisipan tradisi Dulkadiran, di Sampurnan, pada tanggal 5 Maret 2016. 
oleh Mbah Mas,

"Nek Dulkadiran iku sing diwiridno kan nang Sulthanul Auliya'.

Nah beliau iku kan bebat. Karamahnya luar biasa. Karena bebatnya itu, maka selalu diperingati, dengan harapan kita ini selamat." Syekh Abdul Qadir Abilani diyakini memiliki kehebatan dan karamah yang luar biasa. ${ }^{48}$

Sementara itu, Kyai Bukhari menjelaskan bahwa wasilab kepada Syekh Abdul Qadir Aljilani merupakan salah satu ibadah, melaksanakan perintah Allah:

'Dadi menyebut ulama' atau auliya' itu karena memang kita diperintah untuk memuliakan mereka. Alulama' warasatul anbiya', nek memuliakan ulama' berarti juga memuliakan Nabi, muliakno Nabi berarti nuruti perintahe Allah. Jangan dianggap meminta, mintanya pada Allah, tapi mereka lantarannya. Katakanlah seperti minum air. Kita minum airnya Allah, tapi kita tidak bisa langsung ngokop nang sumur, gimana? Lantaran gelas, lantaran sanyo. Tetap minumnya milik Allah tapi nganggo lantaran gelas, hakikate tetep minta Allah. Lha ngoten loh."

Dari penjelasan di atas, dapat dimengerti bahwa para ulama' atau auliya' yang disebut di dalam tradisi Dulkadiran adalah salah satu cara untuk melaksanakan perintah Allah. Menurut Kyai Bukhari, ulama' adalah pewaris para nabi. Jika memuliakan ulama' itu artinya memuliakan juga para Nabi, jika ini dilakukan berarti telah melakukan perintah Allah.

\section{Simbol 3: Nasi Uduk dan Ayam Jago}

Simbol nasi uduk dan ayam jago dirumuskan dari konsep memuliakan ulama. Menurut Kyai Bukhari, hidangan ini adalah makanan favorit Syekh Abdul Qadir Aljilani. Untuk menghormati dan ngalap berkah, makanan ini dijadikan sebagai makanan khas yang selalu ada di setiap pelaksanaan Dulkadiran. Hidangan ini merupakan bagian dari ijazah yang berasal dari Kyai Cholil. ${ }^{49}$

${ }^{48}$ Wawancara dengan Nyai Hj. Mashfiyah Sholih, sesepuh masyarakat Sampurnan, di Sampurnan, pada tanggal 25 Desember.

49 Diolah dari hasil wawancara dengan K.H. Ahmad Bukhari Hadi, pada tanggal 
Terkait dengan hal ini, Juwairiyah, salah satu masyarakat yang sering membaca manaqib Syekh Abdul Qadir Aljilani menjelaskan, bahwa hidangan nasi uduk dan ayam jago yang menjadi makanan khas tradisi Dulkadiran memiliki keterkaitan dengan karamah yang dimiliki Syekh Abdul Qadir Aljilani:

"Umumnya, orang yang menyelenggarakan Dulkadiran itu masak nasi uduk dan ayam. Karena di sini itu - kitab manakib Nur alBurbaniy - ada penjelasan begini, ketika Syekh Abdul Qadir punya murid, muridnya diperintahkan untuk tirakat dengan makan yang tidak enak dan beberapa hal lain juga tidak enak. Akhirnya murid itu dijenguk oleh ibunya. Ibunya tidak tega. Dia melihat Syekh Abdul Qadir makan ayam. Lalu dia protes. Kemudian Syekh Abdul Qadir biacara pada ayam - yang sudah menjadi hidangan - "Hai ayam, bangunlah!". Seketika, ayam yang sudah dimasak itu bangun, lalu berkokok. Berkokoknya itu dengan mengeluarkan suara "Laa ilaaha illallaah mubammadurrasulullah Syekh Abdul Qadir waliyullah". Orang tuanya kaget, lalu Syekh Abdul Qadir berkata, "jika putra anda sudah bisa memiliki ilmu seperti ini, maka dia boleh makan ayam." ${ }^{50}$

Simbol-simbol yang dirumuskan tersebut, disampaikan oleh pemilik otoritas -para Kyai - kepada masyarakat. Para Kyai menyampaiakan simbol yang menawarkan suatu gaya hidup atau tindakan yang didasarkan pada hadith Nabi dengan cara persuasif. Gaya hidup atau tindakan yang disarankan oleh simbol-simbol tersebut diwujudkan dalam bentuk pelaksanaan tradisi Dulkadiran.

\section{Motivasi dan Perasaan}

Menurut Geertz, motivasi adalah "suatu kecenderungan yang tahan lama, suatu kecondongan yang terus-menerus muncul untuk menampilkan jenis-jenis tindakan tertentu dan mengalamijenis-jenisperasaan tertentu dalam jenis situasi-situasi

27 April 2015.

50 Diterjemahkan dari hasil wawancara dengan Juwairiyah, sesepuh masyarakat Sampurnan, di Sampurnan, pada tanggal 25 Desember 2015. Kisah ini bersumber dari Muslih bin 'Abdurrahman, Alnur Alburhani (Semarang: Karya Toha Putra, n.d.), 59. 
tertentu". ${ }^{11}$ Dalam konteks ini, masyarakat Sampurnan mengenal konsep tentang keutamaan memuliakan ulama, berbuat baik kepada kedua orang tua, dan keutamaan membaca Alqur'an. Konsep-konsep ini memunculkan aura faktualitas dan dirumuskan ke dalam simbol-simbol. Simbol-simbol yang dirumuskan itu, disampaikan secara persuasif oleh para Kyai. Mereka mengajarkan, mengajak, dan memberikan ijazah kepada generasi penerus agar menjalankan tradisi Dulkadiran ini. Penyampaian simbol-simbol tersebut, kemudian memotivasi seseorang untuk melaksanakan tradisi Dulkadiran.

Lucha misalnya, menyelenggarakan Dulkadiran karena termotivasi oleh kemuliaan yang dimiliki oleh Kyai Bukhari. Selain itu, kehebatan dan karamah yang dimiliki oleh Syekh Abdul Qadir Aljilani juga menjadi motivasi mereka. Sebagaimana disampaikan oleh Mbah Mas bahwa dengan tawassul kepada salah satu wali Allah yang dikenal sebagai Sultan Alauliya', doa untuk keselamatan yang mereka mohonkan, itu lebih mudah dikabulkan oleh Allah. ${ }^{52}$

Motivasi lain didorong oleh adanya konsep tentang birru al-walidain, dengan cara melanjutkan tradisi yang telah dilakukan oleh orang tua. $\mathrm{Bu}$ Bar misalnya, beliau berusaha untuk patuh dan tidak memiliki keberanian untuk meninggalkannya:

"Ya tetap dijalankan karena bacaannya itu kan baik, kalimat-kalimat thayyibah. Dan karena itu kan kebiasaan, adat yang telah dilakukan oleh orang-orang tua. Sebagai anak dan cucu, istilahnya ya penerus lah, saya itu kok ya gak wani ninggal tradisine orang tuo. Wes pokok e nurut, dilakoni wae ta opo sing dilakokno wong tuo iku." ${ }^{53}$

Berbeda dengan kedua hal di atas, Kyai Bukhari termotivasi oleh perintah-perintah agama yang disampaikan oleh Alqur'an dan hadith.

\footnotetext{
51 Clifford Geertz, Kebudayaan dan Agama (Terj), 14.

52 Wawancara dengan Ibu Nyai Hj. Masfiyah Sholih, pada tanggal 25 Desember 2015.

53 Wawancara dengan Ibu Nyai Hj. Barrotut Taqiyyah, pada tanggal 26 April 2016.
}

AL-A'RAF - Vol. XIV, No. 2, Juli - Desember 2017 
Baginya, Allah adalah pusat segala aktivitas. Memuliakan atau memuji Syekh Abdul Qadir Aljilani yang dilakukan dalam tradisi Dulkadiran merupakan perintah Allah. Sama halnya dengan perintah Allah untuk bershalawat, dan memuji Nabi Muhammad. Begitu juga dengan membaca Alqur'an yang merupakan perintah Allah. Dengan demikian, beliau melakukan Dulkadiran karena termotivasi oleh perintah Allah untuk memuliakan ulama dan membaca Alqur'an.

Motivasi-motivasi di atas terus-menerus muncul di lingkaran kehidupan masyarakat Sampurnan. Sehingga mereka terdorong untuk melaksanakan tradisi Dulkadiran, terutama saat musim haji dan menjelang acara penting. Di dalam definisinya tentang motivasi, Geertz menjelaskan bahwa kecenderungan yang terus-menerus muncul ini, mendorong seseorang untuk melakukan tindakan tertentu, dan memunculkan perasaanperasaan tertentu dalam situasi tertentu. Tetapi perasaan ini dapat berubah sesuai dengan situasi yang dialami oleh seseorang. ${ }^{54}$ Dengan didasari motivasi-motivasi tersebut, pelaksanaan tradisi Dulkadiran yang dilakukan oleh masyarakat Sampurnan, dalam berbagai situasi memunculkan perasaan atau suasana hati tertentu.

Ketika menyelenggarakan tradisi Dulkadiran untuk mendoakan anaknya yang sedang melaksanakan ibadah haji, Bu Kho merasakan ketenangan hati karena telah melakukan ikhtiyar untuk meminta keselamatan kepada Allah. ${ }^{55}$ Tradisi Dulkadiran yang dilaksanakan dalam suasana kebersamaan yang khusuk, dapat memunculkan perasaan tenang dalam hati. Sebagaimana pengalaman $\mathrm{Bu}$ Bar saat menyelenggarakan tradisi Dulkadiran menjelang pelaksanaan haul masyayikh. Ia merasa tidak berani meninggalkan tradisi yang telah dilaksanakan oleh orang tua dan sesepuhnya. Ia khawatir, jika meninggalkan tradisi ini menjelang pelaksanaan haul akan terjadi sesuatu yang tidak diinginkan, yang dapat menghambat kelancaran pelaksanaan haul. Sehingga, ketika beliau melaksanakan tradisi

${ }^{54}$ Clifford Geertz, Kebudayaan dan Agama (Terj), 12

55 Diolah dari hasil wawancara dengan Ibu Hj. Khoiriyah, pada tanggal 24 Desember 2015. 
Dulkadiran, beliau merasakan ketenangan dan perasaan lega karena telah melanjutkan tradisi orang tua. ${ }^{56}$

Sedikit berbeda dengan beberapa informan sebelumnya, saat Aswadi mengikuti tradisi Dulkadiran, ia memiliki pengalaman seolah menemukan ruh kehidupannya. Baginya, setiap Surat Alqur'an dan zikir yang dibaca saat Dulkadiran, memiliki ruh tersendiri. Dengan membacanya secara bersamasama dalam suasana yang khidmat, beliau menemukan serpihan ruh kehidupan yang dapat memotivasi beliau untuk selalu mengembangkan diri. $^{57}$

\section{Secara Unik Terlihat Realistis}

Perasaan yang dialami atau dirasakan oleh masyarakat Sampurnan ketika melakukan tradisi Dulkadiran, pada tahap selanjutnya direfleksikan dalam kehidupan sehari-hari mereka. Melalui perasaan yang muncul tersebut, agama membentuk suatu tatanan kehidupan. Pelaksanaan tradisi Dulkadiran memiliki implikasi sosial. ${ }^{58}$ Melalui pelaksanaan Dulkadiran, konsep-konsep yang dirumuskan dalam simbol, seolah-olah menegaskan kebenarannya.

Ketika Bu Bar tidak melaksanakan tradisi yang biasa dilakukan oleh orang tuanya, jika terjadi suatu hal yang tidak diharapkan, orang lain akan mengaitkannya dengan tradisi tersebut. Masyarakat mempercayai, bahwa jika tidak melakukan tradisi Dulkadiran menjelang haul masyayikh, maka akan terjadi hal yang tidak diinginkan. Sebaliknya, dengan melaksanakan tradisi Dulkadiran, ketenangan dan rasa optimis akan muncul dalam diri masyarakat. Dengan demikian, mereka akan percaya bahwa segala sesuatunya akan berlangsung dengan lancar. ${ }^{59}$

56 Diolah dari hasil wawancara dengan Ibu Nyai Hj. Barrotut Taqiyah, pada tanggal 26 April 2016.

57 Diolah dari hasil wawancara dengan Bapak Aswadi, pada tanggal 25 Desember 2015.

58 Clifford Geertz, Kebudayaan dan Agama (Terj), 41.

59 Diolah dari hasil wawancara dengan Ibu Nyai $\mathrm{Hj}$. Barrotut Taqiyah, pada tanggal 26 April 2016. 
Begitu juga dengan yang dialami oleh Aswadi. Ketika melaksanakan Dulkadiran, ia seolah menemukan ruh kehidupannya lewat surat-surat Alqur'an yang dibaca. Ruh yang ditemukannya itu dapat memotivasinya untuk mengembangkan potensi diri, dan meraih hal-hal yang diinginkannya. Baginya, Dulkadiran adalah tawassul kepada Syekh Abdul Qadir Aljilani yang bertujuan untuk menguatkan keimanan dan mendekatkan diri kepada Allah. Ketika seseorang sudah dekat dengan Allah, maka hal lain yang berada di luar jangkauan nalar manusia pun dapat terjadi. ${ }^{60}$ Ini merupakan refleksinya dari apa yang dialami oleh Syekh Abdul Qadir Aljilani, karena kedekatannya dengan Allah dapat mengalami hal yang luar biasa, termasuk yang menurut nalar manusia tidak mungkin terjadi.

Perasaan yang menciptakan suatu tatanan kehidupan inilah yang menjadikan pelaksanaan tradisi Dulkadiran secara unik terlihat realistis. Konsep yang mendasari pelaksanaan tradisi Dulkadiran terlihat nyata dalam kehidupan masyarakat Sampurnan. Perasaan yang direfleksikan dalam kehidupan itu, seolah-olah membenarkan konsep tersebut. Dengan demikian, simbol-simbol yang dirumuskan dari konsep-konsep agama, yang dilibatkan dalam pelaksanaan tradisi Dulkadiran memotivasi seseorang untuk melaksanakannya, sehingga memunculkan perasaan tertentu, yang direfleksikan dalam kehidupan masyarakat, secara unik terlihat sebagai sesuatu yang realistis.

\section{Penutup}

Sebagai salah satu fenomena living qur'an, resepsi pembacaan suratsurat Alqur'an dalam tradisi Dulkadiran yang dilakukan oleh masayarakat Sampurnan memiliki makna tersendiri. Melalui teori interpretasi budaya Clifford Geertz, dapat disimpulkan bahwa masyarakat Sampurnan mengenal konsep tentang kemuliaan ulama, birru Alwalidain, dan

${ }^{60}$ Diolah dari hasil wawancara dengan Bapak Aswadi, pada tanggal 25 Desember 2015 
keistimewaan Alqur'an. Konsep-konsep tersebut didasarakan pada landasan agama yang mempunyai ultimate meaning sebagai cara untuk mendapatkan keselamatan, pahala, syafaat, dan surga. Konsep-konsep itu kemudian dipercaya sebagai konsep yang benar dan nyata. Selanjutnya, konsep-konsep ini dirumuskan dalam bentuk simbol surat-surat Alqur'an, tawassul kepada Syekh Abdul Qadir Aljilani, hidangan berupa nasi uduk dan ayam jago. Simbol-simbol tersebut memiliki makna yang kembali kepada konsep-konsep tersebut. Simbol-simbol tersebut menyarankan suatu gaya hidup atau tindakan, yang disampaikan oleh para Kyai secara persuasif. Selanjutnya, konsep-konsep tersebut memotivasi masyarakat untuk melakukan tradisi Dulkadiran. Pelaksanaan tradisi ini kemudian memunculkan perasaan dalam diri seseorang. Perasaan yang dialami ketika melakukan tradisi Dulkadiran ini kemudian direfleksikan dalam kehidupan sehari-hari, seolah-olah membenarkan konsep yang ada, sehingga perasaan tersebut secara unik terlihat realistis.

\section{Referensi}

'Abdurrahman, Muslih bin. Alnur Alburhani. Semarang: Karya Toha Putra, n.d.

Al-'Asqalani, Ibnu Hajar. Almatlab Al'aliyah. Jilid 7. Beirut: Dar Alkutub Alilmiyyah, 2003.

Al-Baihaqi. Syu'bu Aliman. Jilid 2. Beirut: Dar Alkutub Alilmiyyah, 2000.

Al-Durais. "Fadail Alqur'an," n.d.

Al-Nawawi, Al-Azkar. Tilawah Alqur'an No. 323. Beirut: Dar Alfikr, 1994.

—. Tilawah Alqur'an No. 323. Beirut: Dar Alfikr, 1994.

Al-Qayyum, Abd. Safahat fi "Ulumi Alqira"ah. Makkah: Almaktabah Alimdadiyyah, 2001.

Al-Qurtubi. "Altizkar Fi Afdalli Alazkar,” n.d.

Al-Tirmizi, Sunan Altirmizi. "Kitab Fadail Alqur'an 'an Rasulillah No. 2835," n.d. 
Alsuyuti. Lubab Alhadith. Surabaya: Nur Alhuda, n.d.

Clifford Geertz. The Interpretation of Cultures. USA: Basic Books, 1973.

Djabir, Abdul Rauf. Dinamika Pondok Pesantren Qomaruddin. Gresik: YPP Qomaruddin, 2014.

Geertz, Clifford. Kebudayaan Dan Agama (Terj). Edited by Francisco Budi Hardiman. Yogyakarta: Kanisius, 1992.

Kafid, Nur. "From Personal to Social Transformation: A Phenomenological Study on the Life of 'Kyai Kampung."' JURNAL KOMUNITAS: Research \& Learning in Sociology and Anthropology 6, no. 2 (2014): 336-344.

Masyhuri, A. Aziz. Ensiklopedi 22 Aliran Tarekat. Surabaya: Imtiyaz, 2014.

Muslim, Sahih. "Kitab Salatu Almusafirin No. 1337," n.d.

Mustaqim, Abdul. Metode Penelitian Alqur'an dan Tafsir. Yogyakarta: Idea Press Yogyakarta, 2014.

Pals, Daniel L. Seven Theories of Religion, n.d.

Rafiq, Ahmad. "Sejarah Al-Qur'an: dari Pewahyuan ke Resepsi (Sebuah Pencarian Awal Metodologis)." In Islam, Tradisi dan Peradaban, edited by Sahiron Syamsudin, 73. Yogyakarta: Suka Press, 2012.

Salam, Alqasim bin. "Fadail Alqur'an Wa Ma'alimuhu Wa Adabuhu," n.d.

Shihab, Quraish. Wawasan Alqur'an Tentang Dzikir dan Doa. Jakarta: Lentera Hati, 2006.

Syam, Nur. Islam Pesisir. Yogyakarta: LkiS, 2005.

- Madzhab-Madz̧ab Antropologi. Yogyakarta: LKiS, 2011.

Ta'rifin, Ahmad. "Tafsir Budaya atas Tradisi Barzanji dan Manakib." Penelitian 7, no. 2 (2010).

Voorst, Van. "Kajian Naskah dan Kajian Living Qur'an dan Living Hadith.” Journal of Qur'an and Hadith Studies 4, no. 2 (2015): 151. 
192 | Nilna Fadlillah

AL-A'RAF - Vol. XIV, No. 2, Juli - Desember 2017 